\title{
Fenomenología
}

\section{Terapia alternativa}

\section{Alternative therapy}

\section{Terapia alternativa}

Concepción García De las Bayonas Blánquez

Relato finalista X Edición Premio Vida y Salud de Relatos (modalidad absoluta).

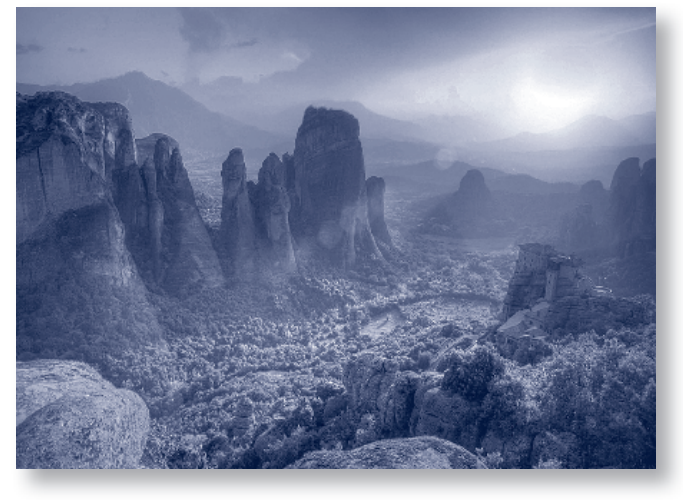

Laura estaba llenando el depósito de un Audi A3 en la gasolinera en donde trabajaba. Un coche entró en la estación de servicio y paró. El pasajero que había en la parte de atrás del vehículo abrió la puerta y, una pelota cayó fuera del mismo. Inmediatamente una bola grande, peluda, de color blanco y marrón, salió detrás de ella. Tenía que correr, agarrarla con la boca y, después, colocarla a los pies de la persona que se la había tirado. Siempre era igual: pelota, carrera, pies del amo, caricia; pelota, carrera... ahora algo no cuadraba. Su amo había olvidado cómo terminaba el juego y arrancó el coche antes de que él regresara. De repente, Laura se dio cuenta de la jugada: habían abandonado otro cachorro $y$, con este, ya iban cuatro en poco tiempo.

-¡No, otra vez no! dijo indignada; corrió detrás del vehículo hasta que se dio cuenta de que era inútil. El perro la miraba, con la pelota en la boca, totalmente desorientado; no sabía qué hacer. Al principio, el chucho siguió el rastro del coche durante un rato intentando alcanzarlo. Después, perdió la esperanza de lograrlo y volvió dónde estaba ella. Se compadeció del pobre perro; lo vio tan desamparado que se acercó a él y lo acarició para tranquilizarlo, le habló en voz baja y le puso un cacharro con agua, que el animal bebió con avidez. Esperó un rato para ver si los dueños del can volvían a por él, aunque en el fondo, sabía que eso casi nunca ocurría. Ya tenía recogidos tres animales abandonados; no podía alimentar a más. El perro no sabía dónde dormir, necesitaba su cesta con su cojín. Estuvo buscando un sitio, en donde recostarse, hasta que agotado por el miedo y el cansancio se quedó dormido debajo de un coche. Laura tenía que buscar una solución para que no fuera atropellado cuando se cruzase de un lado a otro de la carretera. De repente le vino a la cabeza la persona que podría resolverle el problema: por las noches oía su programa casi a diario y sabía lo comprometida que estaba con el mundo de los animales; la locutora buscaría una solución. Cogió el teléfono decidida a contar el caso.

Berta, esa noche como otras, estaba desvelada; le costaba mucho dormirse. Su situación actual, no era precisamente la adecuada para 
tener felices sueños. Acababa de terminar con los tratamientos de quimioterapia y la vacuna contra el cáncer de pecho, después de una operación en dónde le habían extirpado un tumor y varios ganglios del brazo. Eso ya de por sí, es bastante traumático y necesita todo el apoyo familiar, pero ella también había terminado con otra situación que la había amargado durante bastante tiempo: su matrimonio. Dijo-¡Basta! en aquel momento; por eso ella también estaba perdida. Debía organizar su vida de nuevo. Los médicos le habían aconsejado que no era la mejor época para una separación sobre todo cuando estaba, además, a punto de jubilarse. El momento era muy crítico. Ella lo sabía y sus hijos también pero se dijo:

-Más vale estar sola que mal acompañada y, esta vez, fue la definitiva. A partir de entonces, cualquier decisión que tomase sería responsabilidad suya y de nadie más. Pedro y Virginia ya eran mayores y vivían independientes, pero insistían en que se dejase aconsejar por una psiquiatra para no caer en una depresión. Berta rechazaba esta idea: no quería más visitas a médicos nuevos. Tenía que hacerse tantas revisiones y tan continuas, provocadas por su enfermedad, que la idea de agregar a la lista una revisión más, la echaba para atrás. Sin embargo, necesitaba algo que le diera ánimo para levantarse cada día con optimismo y, ella sola no encontraba aquella chispa que hacía tiempo había tenido y que le había hecho superar cualquier contrariedad por grande que hubiera sido. Por eso, cuando se despertaba de madrugada y empezaba a repasar las últimas etapas de su vida, se espabilaba de tal forma que ya no había posibilidad de dormirse. Aquella noche era una de esas, así que conectó la radio y sintonizó una emisora que de vez en cuando oía de madrugada. Aunque algo adormilada, pudo escuchar a Laura contar el caso del perro que tenía recogido en su gasolinera. Ella acababa de exponer el problema:

-No puedo hacerme cargo de más animales. Si alguien necesita un perro que llame a esta emisora y ellos les darán mi dirección. Como solución provisional, desde el programa localizaron un refugio que estaba cercano a la gasolinera, para que fueran a recogerlo. Pero este centro estaba tan saturado, que dijeron que no podían tenerlo indefinidamente porque estaban escasos de medios económicos para alimentarlo, sin embargo la locutora del programa, tan solidaria y tan sensible con estas situaciones, habló por las ondas:

-Si alguien que me esté oyendo necesita un animal de compañía, ahora es el momento. Yo me comprometo a hacerme cargo de todos los gastos y a acompañar a esta persona al refugio a recogerlo en el momento en que nos llamen diciendo que ya lo tienen en sus instalaciones.

Berta todavía no se explica cómo medio dormida, pudo retener el teléfono que dijeron por la radio. Estuvo unos minutos recapacitando: sabía que sus hijos iban a poner el grito en el cielo, que dirían que estaba muy delicada y que tendría que madrugar todos los días para sacarlo. y que con cuidar de sí misma ya tenía bastante pero, ella necesitaba algo, un aliciente que la obligase a mantenerse activa y a salir a la calle aunque hiciera mal tiempo. Por otro lado hacía poco tiempo había leído unos estudios realizados por la Universidad de Alabama en los que decían que la compañía de un perro era más beneficiosa que una terapia psicológica y que además, aumentaba la calidad de vida de su dueño sobre todo cuando eran mujeres que vivían solas. Estaba segura, esa petición de ayuda era para ella, por eso recordaba el teléfono y por eso esa noche estaba despierta. Marcó el no que habían dado por la emisora: 


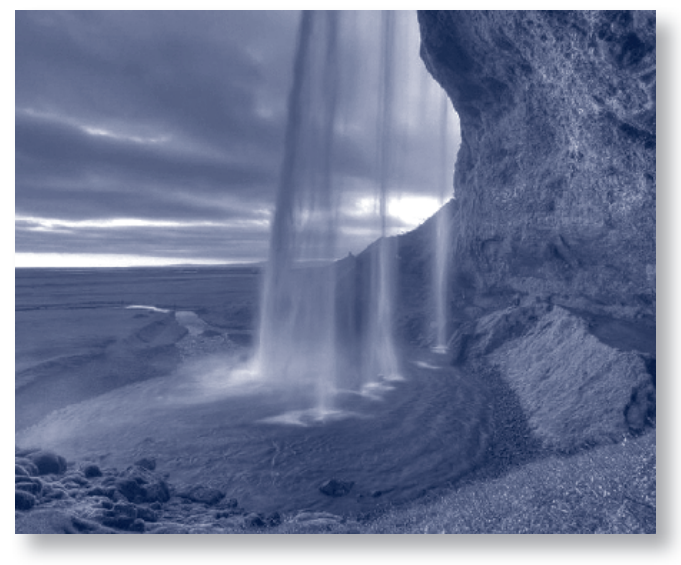

-Ya tenemos una señora que se queda con el perro, oyeron todos los que en ese momento tenían sintonizado el programa. La alegría de la locutora se hizo patente por las ondas e inmediatamente pusieron en contacto a Laura con Berta:

-¿Laura? Mire, yo me quedo con él; en el momento que lo tengan en el refugio vamos a buscarlo.

-No sabe la alegría que me da. No se puede imaginar la cantidad de perros que abandonan todos los días en la carretera. A veces los que parecen animales son las personas.

Pasó casi un mes y medio desde que Berta aceptó quedarse con el perro, hasta que los voluntarios del refugio pudieron capturarlo. Laura los llamó cuatro veces diciendo que el perro había vuelto y que podían ir a por él, pero cuando ellos llegaban, se les escapaba como si hubiera estado toda su vida acostumbrado a huir de alguien. Un día, apareció hecho una calamidad; se notaba que lo habían tenido atado y le habían pegado. Llegó con las orejas gachas y el rabo entre las patas. Cuando lo vio de esa manera se acercó y el perro se dejó acariciar por ella.

-Buen chico, tranquilízate, ya hemos encontrado a una persona que te va a querer mucho, le decía mientras le sujetaba con cuidado e iba andando con él hacia el lugar en donde tenía una correa.

-Ya lo tengo; ahora no se escapará porque lo he atado. Podéis venir a por él. Al día siguiente, Berta recibió una llamada de la locutora:

-Berta, soy Rosa; ya tienen al perro, podemos ir a recogerlo.

Al oírla, se puso nerviosa, tenía muchas ganas de tenerlo en casa: algo la decía que aquello iba a ser su mejor medicina. Era noviembre y hacía bastante fresco; cuando llegaron al Centro de Recogida, que estaba en la provincia de Burgos, el veterinario las estaba esperando con Pepe: ese era el nombre que le habían puesto en el refugio. El primer momento fue de nervios y de tanteo, tanto por parte de Pepe como de su nueva ama. A ella le pareció un poco más grande de lo que esperaba y le dio un poco de miedo pensar que no pudiese dominarlo cuando lo sacase a pasear, pero el pobre ¡ estaba tan delgado! Lo acarició y el perro se dejo hacer; al pasarle la mano por el lomo le notó todas las costillas.

-Es de raza grifón, dijo el veterinario. Le hemos puesto ese nombre pero usted se lo puede cambiar. No sabemos si habrá adquirido algunos vicios que hagan incompatible su vida en familia, por eso no le hemos colocado el chip todavía. Si usted ve que por cualquier causa, no puede hacerse cargo de él, ¡Por favor! nos lo trae otra vez, pero no lo abandone.

-No se preocupe, nunca lo dejaría. Lo que sí haré será cambiarle el nombre; con un Pepe en mi casa ya tuve bastante.

Rosa y Berta metieron a Pepe en el coche. No les costó ningún trabajo, le taparon con una manta y se acurrucó tan a gusto. Hacía tiempo que no se sentía así, tan mimado y querido. Las dos iban contentas pensando que el perro también lo estaba. Lo malo fue sacarlo del vehículo cuando llegaron a Madrid. Todavía hay vecinos que recuerdan la llegada: 
era muy gracioso ver como intentaban moverlo del coche a empujones. Pepe se aferraba al asiento sin querer salir de allí. ¡Pobre! pensaba que otra vez iba a empezar su calvario. Por fin, empujándolo de nuevo, pudieron meterlo en el ascensor y con mucho esfuerzo entrarlo en casa. La vecina del noveno, cuando la ve, siempre le comenta lo mismo:

-Berta, no te puedes ni imaginar lo cómicas que estabais las dos peleando con el pobre chucho. ¡Menos mal que no os mordió!

-Bueno, ya estás en tu nuevo hogar, dijo cerrando la puerta, veremos si te adaptas a él. Estuvo acariciándolo durante un rato, después le puso comida, agua y un cojín para que durmiese cómodo. La primera noche, Pepe se quedó en la puerta de entrada y no consintió moverse de allí. Tampoco comió nada, estaba muy asustado, solo bebió agua. Berta también lo estaba, no sabía cómo iba a resultar la experiencia, pero el perro, cuando se acostumbró al calorcito de la calefacción, durmió como un tronco; fue ella la que no pegó ojo en toda la noche. Al día siguiente, observó que no se había movido del sitio en dónde lo dejó. Al poco tiempo llegaron sus hijos para conocerlo y después la acompañaron al veterinario. Allí eligieron un nombre nuevo: le llamaron Bobby. Ese día Bobby, entro un poco al salón; con mucho cuidado iba oliendo y fisgoneándolo todo. Solo cuando llevaba un día y medio, se acercó a Berta, que estaba viendo la televisión y apoyó su cabecita sobre las rodillas de su nueva dueña. A ella le dio un vuelco el corazón: por fin estaban conectando. Bobby se fiaba de nuevo de la raza humana. A partir de aquel día la vida de los dos cambió mucho: ella prefirió la compañía del pobre animal a las visitas al psicólogo, los paseos con Bobby al Prozac y al Transilium y las tertulias de vecinos con perros, a las sesiones de diván del psiquiatra. Ahora en estas reuniones, ha conocido a muchos veci- nos; se cuentan sus problemas personales y, se ayudan unos a otros.

Berta, todas las tardes, camina durante bastante rato acompañada por su nuevo amigo, a veces también va su hija con ellos. Son paseos agradables, sin nadie que la juzgue ni que se interponga en su paz interior, ideales para mejorar su estado de ánimo. No sabe si el perro la encontró a ella o ella encontró al perro. Pero está segura de que la mejor terapia que podía hacer para recuperar su alegría ha sido adoptarlo. Ahora no se encuentra sola, tiene un compañero de piso que le da amor incondicional sin pedir nada a cambio y, hasta puede ser a veces, su confidente.

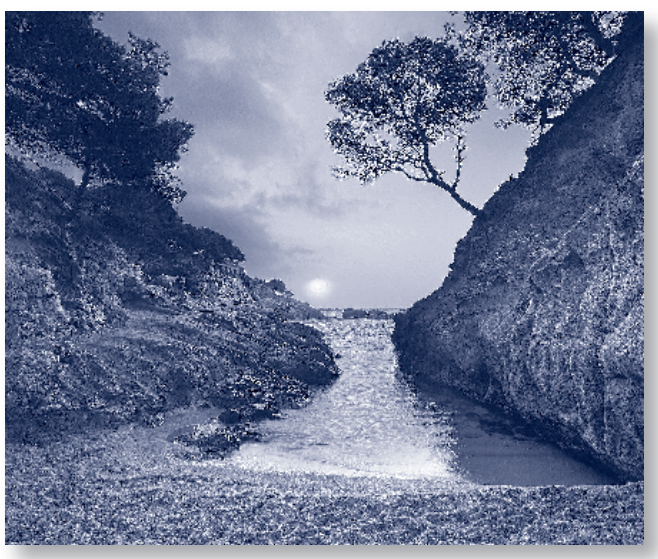

